\title{
Amamentação exclusiva de recém-nascidos prematuros: percepções e experiências de lactantes usuárias de um serviço público especializado
}

\author{
Achieving exclusive breastfeeding of premature \\ babies: the perceptions and experience of \\ women from public health services
}

Danielle Freitas BRAGA ${ }^{1}$

Márcia Maria Tavares MACHADO'

Maria Lúcia Magalhães BOSI ${ }^{1}$

RE S U M O

\section{Objetivo}

Investigar percepções e vivências das mães de recém-nascidos prematuros que amamentaram exclusivamente do $4^{\circ}$ ao $6^{\circ}$ mês de vida.

\section{Métodos}

Estudo seccional exploratório, fundamentado no método qualitativo. Utilizaram-se entrevistas não-diretivas, individuais, junto a oito mulheres, mães de prematuros atendidas no ambulatório de follow-up da Maternidade Escola Assis Chateaubriand, serviço vinculado ao Sistema Único de Saúde. A análise temática das falas apontou um eixo em torno do qual foram agrupados quatro núcleos de sentido: os sentimentos das mães ao vivenciarem o contato inicial com os recém-nascidos prematuros; o apoio dos profissionais às mães de prematuros; a decisão das mães de prematuros em amamentar exclusivamente e a convivência com o método mãe-canguru.

\section{Resultados}

A análise revelou que cada mãe vivencia o aleitamento materno exclusivo de maneira singular. A decisão de amamentar o prematuro está relacionada ao reconhecimento da importância do leite materno para a saúde do filho. Contudo, o suporte fornecido pela Instituição, a partir do apoio dos profissionais às mães de prematuros, tal como se observa no serviço analisado, revela-se como elemento decisivo para a prática exclusiva do aleitamento materno.

\section{Conclusão}

Amamentar exclusivamente os prematuros ainda é um desafio para algumas mães, mas é possível, desde que haja determinação, suporte apropriado da família, da rede social e, em especial, dos profissionais de saúde.

Termos de indexação: Aleitamento materno. Pesquisa qualitativa. Prematuro.

\footnotetext{
${ }^{1}$ Universidade Federal do Ceará, Faculdade de Medicina, Departamento de Saúde Comunitária. R. Prof. Costa Mendes, 1608 $5^{\circ}$ andar, Rodolfo Teófilo, 21943-570, Fortaleza, CE, Brasil. Correspondência para/Correspondence to: M.L.M. BOSI. E-mail: <malubosi@secrel.com.br>.
} 
294 | D.F. BRAGA et al.

\section{A B S T R A C T}

\section{Objective}

To investigate perceptions and experiences of mothers of premature babies who breastfed exclusively from the $4^{\text {th }}$ to the $6^{\text {th }}$ month of life.

\section{Methods}

This was a cross-sectional exploratory study, based on qualitative methodology. Non-directive interviews were conducted among eight women, mothers of premature babies who received care in the School-Maternity Assis Chateaubriand, a service associated with the Federal University of Ceará in Fortaleza. This study is based on the theoretical premises of phenomenology. After transcription, the material was analyzed and classified into four axis of meaning: the mother's experiences at the initial contact with the premature baby; the support given to the mothers of premature babies by the hospital professionals; the mother's decision to breastfeed exclusively and the kangaroo care experience.

\section{Results}

The results revealed that each mother had a unique experience of breastfeeding. For these women, the decision to breastfeed the premature baby was strongly related to their acknowledging the importance of this practice for the child's health. However, the support given by the institution and the professionals to the mothers of premature babies, as observed in the analyzed service, is a decisive element for exclusive breastfeeding.

\section{Conclusion}

Exclusive breastfeeding of premature babies is still a challenge for some mothers; however, it is possible as long as there is motivation and support from the family, from the social network, and especially from health professionals.

Indexing terms: Breast feeding. Qualitative research. Infant, premature.

\section{N T R O D U ÇÃ O}

Nos países em desenvolvimento, a desnutrição, bem como as infecções intestinais e respiratórias, persiste como principal responsável pelas condições desfavoráveis de saúde de parcela expressiva da população infantil, tendo como conseqüência taxas ainda elevadas de mortalidade ${ }^{1,2}$.

Em regiões como o Nordeste brasileiro, onde é grande o número de nascimentos de crianças prematuras e de baixo peso ${ }^{3}$ e a duração da amamentação é ainda pequena, a prática exclusiva e prolongada do aleitamento materno pode contribuir para o declínio dos níveis da mortalidade infantil. No Ceará4, dados de 2006, evidenciam que cerca de $70 \%$ das crianças menores de 4 meses recebem exclusivamente leite materno, sendo que $28 \%$ das crianças na mesma faixa etária estavam em aleitamento predominante ou misto.

Tem-se destacado que a qualidade do alimento é fundamental para a sobrevivência de crianças de alto risco ao nascer, como é o caso do prematuro. De acordo com o Fundo das Nações Unidas para a Infância, no mundo nascem, por ano, 20 milhões de recém-nascidos prematuros e com baixo peso, dos quais um terço morre antes de completar o primeiro ano de vida ${ }^{3}$. Nove em cada 10 recém-nascidos com peso inferior a $1000 \mathrm{~g}$ morrem antes de completar o primeiro mês de vida. Para a sobrevivência dessas crianças o aleitamento materno é fundamental, pois o leite das mães de prematuros, conforme o descrito na literatura, apresenta uma diferença na composição do aporte protéico-energético e dos constituintes imunológicos, em relação ao produzido pelas mães de recém-nascidos nascidos a termo ${ }^{5-7}$.

A literatura aponta alguns fatores que favorecem o declínio da prática da amamentação em prematuros, dentre os quais: a falta de contato precoce mãe-filho e a ausência de amamentação na sala de parto, bem como a permanência prolongada do recém-nascido na Unidade de Terapia Intensiva Neonatal (UTIN) ${ }^{8}$. 
Diante da relevância do aleitamento materno para a redução da morbimortalidade em prematuros e da lacuna na literatura científica sobre este tema, considerou-se importante abordar a referida temática, buscando compreender experiências bem sucedidas de mães que, a despeito dos obstáculos, amamentaram exclusivamente seus filhos prematuros até o intervalo entre $04^{\circ} \mathrm{e}$ o $6^{\circ}$ mês de vida.

\section{MÉ T O D O S}

A natureza do objeto aponta a abordagem qualitativa como a mais adequada, tendo em vista a busca pela profundidade de compreensão de aspectos complexos da dinâmica das relações sociais e a produção simbólica a que se vincula o fenômeno, aqui, focalizado?.

Como vertente epistemológica, utilizou-se a fenomenologia, mais precisamente, o método fenomenológico, por entender que este recurso possibilita o acesso ao vivido da mulher que amamentou sua criança prematura, visando à apreensão do significado atribuído diante dessa experiência ${ }^{10}$.

Em síntese, objetivou-se conhecer e compreender a experiência positiva vivenciada pelas mães de prematuros que mamaram exclusivamente, como fenômeno a ser desvelado. Para tanto, utilizou-se a seguinte questão norteadora: "O que significou para você vivenciar a amamentação exclusiva de seu bebê prematuro?", desdobrada a partir dos conteúdos emergentes nas falas, de modo a buscar uma postura não-diretiva na investigação.

O estudo teve como espaço empírico a Maternidade Escola Assis Chateaubriand (MEAC), situada na cidade de Fortaleza (CE), e primeira a receber o título Hospital Amigo da Criança no Ceará. Foram entrevistadas, ao longo de três meses de trabalho de campo, mães de recém-nascidos prematuros que mamaram exclusivamente entre o $4^{\circ}$ e o $6^{\circ}$ mês de vida, adotando-se os seguintes critérios para composição da amostra: mães de crianças nascidas com peso entre $1800 \mathrm{~g}$ a $2500 \mathrm{~g}$, e idade gestacional menor que 37 semanas completas na data do nascimento, e que estivessem, no máximo, com um ano de idade no momento do estudo, residentes em Fortaleza (CE) e usuárias do serviço público mencionado.

Por "amamentação exclusiva", consideraram-se aquelas situações em que o recémnascido havia recebido ou ainda estava recebendo apenas leite materno, sem acréscimo de nenhum outro alimento líquido ou sólido, inclusive água, com exceção de medicamentos, gotas de sais minerais ou vitaminas, permitindo-se leite de peito ordenhado ou pasteurizado.

Para a escolha da população de estudo, foram utilizados os prontuários médicos do ambulatório da MEAC. Entendendo como número adequado de entrevistas aquele que reflete a totalidade - amostra teórica e não probabilística ${ }^{11}$, no seu dimensionamento, foram entrevistadas, pela pesquisadora principal deste estudo, oito mães de prematuros, no período de agosto a outubro de 2004. As entrevistas foram realizadas em um único encontro com cada informante, no domicílio da mãe, propiciando, assim, maior privacidade e comodidade. As entrevistas foram gravadas, com duração média de 60 minutos, verificando-se momentos de grande emoção das mães ao relatarem o nascimento e situações de cuidado com o filho prematuro. As entrevistas foram transcritas na íntegra conservando-se as expressões de linguagem utilizadas pelas entrevistadas, tendo em vista o estatuto fenomenológico do estudo.

Os núcleos temáticos utilizados para a categorização dos resultados obtidos foram: o sentimento da mãe ao vivenciar o contato inicial com o recém-nascido prematuro; o apoio dos profissionais da maternidade às mães de prematuros; a decisão da mãe do prematuro em amamentar exclusivamente e a convivência com o Método Mãe-Canguru.

O estudo teve aprovação do Comitê de Ética em Pesquisa da Universidade Federal do Ceará (UFC), parecer 86/2004. 


\section{RESULTADOSE DISCUSSÃO}

Foram entrevistadas oito mães na faixa etária entre 17 e 38 anos, sendo apenas uma primípara. Em relação ao estado civil, a metade era casada. Quanto ao grau de instrução, uma era analfabeta, cinco tinham o ensino fundamental incompleto e duas o ensino médio completo. No que se refere à ocupação principal, uma era estudante, uma faxineira e as outras seis, do lar. Quanto ao tempo de aleitamento materno, uma amamentou exclusivamente até o sétimo mês de idade cronológica da criança, duas até o quinto mês e cinco até o sexto mês de vida.

As experiências com a amamentação exclusiva de prematuros, aos olhos de quem as vivenciou, são apresentadas a partir dos núcleos descritos a seguir.

\section{Sentimentos da mãe no contato inicial com o recém-nascido prematuro}

No imaginário das mulheres grávidas, prepondera o desejo de ver o filho nascer saudável, forte, ativo e com bons sinais vitais. A passagem do imaginário para a realidade se dá a partir do parto que, simbolicamente, representa a vida. Quando, inesperadamente, ocorre o nascimento de uma criança prematura e este é, logo ao nascer, separado de sua mãe para receber assistência necessária e especializada, há um grande choque para os pais e a família, fazendo aflorar, principalmente nas mães, sentimentos de culpa, frustração, incompetência, medo e ansiedade ${ }^{12,13}$.

Um dos primeiros desafios enfrentados pelas mães de prematuros é o de se adaptarem ao conflito entre a imagem idealizada e a imagem da criança real, o que não se dá sem sofrimento. Evidenciou-se esse fato no discurso das mães entrevistadas, relativo ao primeiro contato com o filho prematuro:

Foi diferente porque eu não pensei uma neném prematura. Quando eu tive ela, eu não quis nem ver de jeito nenhum, fiquei com medo. [...] Eu fiquei todo o tempo com aquela coisa na minha cabeça: 'Meu Deus do céu, como será ela? Será que ela é normal?'. Aí fiquei imaginando coisas. Eu pensava que era um fetozinho feio, sem sobrancelhas, sem cilios, tinha algum defeito, porque a doutora disse que era muito prematura e eu nunca tinha visto uma neném prematura (C.G.S.).

Reconhece-se que o pós-parto é um período de mudanças emocionais para a mãe, a qual se torna muito emotiva e sensível ${ }^{14}$. Na ocorrência de um parto prematuro, surge um sentimento de frustração, por não poder levar consigo o recémnascido para casa. Diversos sentimentos afloram, dentre eles, o receio de que o filho não sobreviva, adoeça com facilidade ou venha a sofrer efeitos colaterais que promovam seqüelas futuras ${ }^{15}$.

As imagens entre a criança imaginada e a real são tão diferentes que, às vezes, na ocasião da primeira visita, o filho traz surpresas e emoções inesperadas. Esse fato foi descrito pelas mães participantes deste estudo, como se pode observar no excerto abaixo:

Eu senti uma emoção muito grande, porque ela era completamente diferente do que eu imaginava, completamente diferente. Quando vi o rostinho dela miudinho, toda perfeita, já tinha as bochechinhas bem cheinhas, era toda lindinha, o rostinho dela era perfeito (C.G.S.).

A gente nem acredita que aquilo é da gente, aquele bebezinho (A.O.S.).

Os profissionais de saúde devem, neste momento inicial, ajudar a mãe a elaborar o luto pela perda da criança "normal" que esperavam, tentando fortalecer o vínculo com a criança prematura.

Essas mães revelam, fortemente, o medo vivenciado durante o primeiro contato com o filho, quando o visualizam na UTIN. O receio da morte iminente, anunciada pelas características frágeis da criança, se junta à descrição desse ambiente assustador, na fala das mães: 
Quando eu (a) via, eu começava logo a chorar, pra mim ela já ia morrer, que o sofrimento dela estava só se prolongando. [...] Eu pensava que ela ia morrer, porque todo dia era uma coisa diferente: primeiro ela estava só tomando antibióticos, depois veio aquele capacete, depois veio sonda, depois a dieta quase zero, os meus peitos vazando e depois secando, foi tudo aos poucos (H.M.M.).

Observou-se, também, que, no contexto sócio-cultural deste estudo, para as mães entrevistadas, a religiosidade se mostra presente, motivada pela crença de que o Ser Divino dará luz ao novo bebê, servindo, assim, como fonte de consolo. Em alguns depoimentos, havia menções a Deus, demonstrando que adquiriam forças ao confiar na sua capacidade de minimizar as dificuldades advindas da internação de seus filhos:

\begin{abstract}
Eu pensei que ele ia morrer, não ia resistir, mas graças a Deus ele está aqui. Porque, quando eu (o) olhei, cheio de aparelhos em cima dele, só ter fé em Deus mesmo, porque por mim... eu não tinha fé não. [...] Eu pensei que ele ia morrer, porque ele estava cheio de aparelhos, agulhas por todo canto, todo furado. [...] Eu pensava: 'ai, meu Deus, será que ele vai se criar? (M.Z.L.S.).
\end{abstract}

As UTINs são ambientes frios, impessoais e temerosos para os pais que chegam para visitar seu filho pela primeira vez, pois não estão habituados às suas normas e rotinas. Nessa primeira visita, não raro, os pais sofrem um profundo impacto ao verem sua criança em uma incubadora, cheia de fios, com picadas de agulhas pelo corpo, cabeça parcialmente raspada, cercada de vários aparelhos. Essa situação faz aumentar o sentimento de insegurança na mãe, por ter tido um parto prematuro.

\section{O apoio dos profissionais de saúde}

Apesar dos bloqueios emocionais e dos obstáculos já mencionados, os profissionais de saúde devem incentivar as mães de prematuros a ir vê-los o mais cedo possível, orientando-as a tocá-los dentro da incubadora, pois, a partir desse contato, é iniciado o vínculo afetivo mãe-filho. Esse é um processo gradual, mas importantíssimo para iniciar o estímulo à ordenha, procurando manter a produção de leite materno, objetivando o sucesso da amamentação ${ }^{16}$.

A partir das falas das entrevistadas, observou-se a importância do apoio desses profissionais de saúde no estímulo ao contato precoce entre mãe e filho e na intervenção para a manutenção da produção láctea. Constatou-se, ainda, que apenas uma mãe disse não ter recebido orientação das auxiliares de enfermagem durante a internação no berçário, tendo sido orientada enquanto permanecia com seu filho na enfermaria mãe-canguru:
A V. [auxiliar de enfermagem] falava muito de amamentação. Quando uma mãe deixava o peito derramando leite, ela falava: 'meu Deus, vocês estão derra- mando ouro, vocês não sabem como isso é precioso, vocês estão deixando cair!', corria, pegava um copinho pra dar à mãe. Ela também contou a experiência dela: que ela amamentou sem ter tido filho, ela adotou uma criança e amamentou (H.M.M.).

No berçário não me orientaram nada de aleitamento, aprendi tudo no Canguru. [...] (A.O.S.).

Muitos estudos têm demonstrado a dificuldade de mães de prematuros em manter a lactação, em razão da permanência prolongada desses recém-nascidos nas UTINs e da falta de sucção. Portanto, faz-se necessário o apoio dos profissionais de saúde ${ }^{15,16}$.

Para incentivar o aleitamento materno do recém-nascido prematuro, deve-se administrar o leite materno por via gástrica, oferecer ajuda e apoio especial para a manutenção da lactação materna, esclarecendo e fornecendo informações relevantes. Quando possível, iniciar o contato pele-a-pele entre mãe e filho o mais precocemente possível e estimular a sucção direta no seio materno $0^{8,16}$. 
Nos relatos, observou-se a importância da ajuda dos profissionais, em especial, no primeiro momento em que recém-nascido vai ao seio:

Tive dificuldade na primeira vez que ele foi mamar, precisou uma enfermeira (auxiliar de enfermagem) colocar porque, além dele ser muito pequenininho, ele só vivia dormindo, tinha que abrir a boquinha dele pra botar no peito (A.O.S.).

Para mamar tinha que ter ajuda por causa da posição. A posição de botar a cabeça aqui no braço e ela pegar o peito, porque a boquinha é muito pequena e às vezes a gente não tinha muito jeito, mesmo tendo outros filhos, então ela [auxiliar de enfermagem] ajudava bastante a botar o neném no peito. Todas as vezes que precisava, ela ajudava (M.R.T.A.).

O profissional de saúde deve oferecer ajuda prática e emocional, baseada na técnica de aconselhamento, auxiliando a mãe a tomar decisões acerca do que é melhor para ela e sua criança bem como a adquirir autoconfiança em sua capacidade de amamentar ${ }^{14}$.

\section{A decisão da mãe para amamentar exclusivamente o filho prematuro}

A amamentação é um direito da criança e, antes de um dever, um direito da mãe, a quem cabe a escolha da melhor forma de alimentar seu filho, opção que deve ser respeitada pelo entorno familiar e social. Essa escolha, na maioria das vezes, é determinada por vivências transversalizadas pelos contextos biológico, psicológico e o social, ou seja, pelo seu existir no mundo ${ }^{17,18}$.

As entrevistadas expressaram o desejo de amamentar exclusivamente, a partir de explicações e justificativas em proporcionar uma boa condição de saúde e desenvolvimento para o seu filho. É interessante ressaltar que as mães constroem o valor da prática da amamentação, apropriando-se do discurso dos médicos, mas o reinterpretando ${ }^{18,19}$. Sendo assim, os conhecimentos básicos de que o leite materno protege o prematuro de doenças impõem para elas uma responsabilidade a mais, no que diz respeito à necessidade de alimentar seu filho apenas ao seio. Para essas mães, o leite materno significa muito, sobretudo, para o prematuro:

Para os prematuros, a amamentação é tudo. Se Deus deu esse leite para a mãe, é porque tem que ser tem que dar, senão a mãe não ia criar leite; Deus fez assim, Deus já preparou tudo, a mãe já vem com aquele leitinho pronto pra dar à criança. [...] Os prematuros são os que mais precisam de leite materno porque nasceram tão sofridos (E.S.N.).

Amamentação, eu acho muito importante para os prematuros ... dar outro leite, que não seja o nosso, a eles pequenos, é muito perigoso deles pegarem uma infecção. O meu primeiro filho também nasceu prematuro, teve infecção, por isso é que dou o peito a todos (M.R.T.A.).

As vantagens da amamentação para os prematuros são várias, podendo-se destacar as propriedades nutritivas e imunológicas, sua função na maturação gastrintestinal, aumento do desempenho neuro-comportamental, proteção contra infecções, melhor desenvolvimento cognitivo e psicomotor, menor incidência de re-hospitalização e, principalmente, a formação e o aumento do vínculo afetivo mãe/filho ${ }^{8,15}$.

A dimensão mais relevante apontada pelas mães refere-se ao vínculo e ao estabelecimento do contato físico com o recém-nascido:

É bom, é gratificante estar dando a mama a ela, dando com todo o prazer, até hoje em dia eu dou com gosto. Fica apegada demais, é muito bom. [...] Eu dou com o maior prazer. Ela está comendo agora, eu estou sentindo é falta, porque ela está mamando menos, eu sinto aquela falta; eu acho tão bom dar de mamar [...] (E.S.N.).

Eu tenho o maior prazer de dar a mama aos meus filhos, todos dois mamaram, essa aqui vai mamar até quando ela quiser. É bom que eles ficam mais apegados com a gente (C.G.S.). 
A tomada de decisão em amamentar é baseada nas prioridades estabelecidas pela mãe, tendendo ao atendimento das necessidades da criança, que assumem maior importância que as necessidades maternas. Isto a leva a fazer algumas renúncias de modo a priorizar a atenção ao filho, nos seus primeiros meses de vida ${ }^{20}$.

As falas das entrevistadas evidenciam que nenhuma delas teve dificuldade para amamentar, quando do retorno à casa. Isso, em grande parte, foi possível devido ao apoio e suporte prévio dos profissionais da maternidade às mães, escutandoas, compreendendo suas demandas individuais relacionadas à amamentação e oferecendo ajuda prática, quando necessário.

No entanto, foi possível apreender a partir das falas das entrevistadas, que as pessoas próximas (amigas e familiares) forneciam opiniões, não raro, contrárias àquelas repassadas pelos profissionais e pouco motivadoras para o incentivo ao aleitamento materno:

Falaram pra ter mais cuidado, porque ela queria mamar muito, era pra ter cuidado pra ela não sufocar [...] Quando vinham falar alguma coisa, eu ficava calada, na minha, não discutia, nem ligava. [...] $A$ minha prima diz: 'tu vai ficar com o peito lá embaixo de tanto dar a mama', aí eu digo: 'não tem importância, não; eu acho bom, não tem nada a ver'. Beleza, eu não ligo pra isso de jeito nenhum (E.S.N.).

Os vizinhos mandavam sempre dar mamadeira. [...] Minha cunhada dizia 'dá outro leite pra ela que é magrinha, miudinha', aí eu dizia 'não pode, ela é um bebê prematuro, tem que ser meu peito mesmo'. Quando ela chegava com essa conversa, eu me lembrava logo das palestras de amamentação que eu assistia no berçário (M.R.T.A.).

Tais contradições também se apresentam para outras lactantes; contudo, a mãe de um prematuro vivencia situações especiais, diferentes daquelas de crianças nascidas a termo, tornando-a mais vulnerável, dada a insegurança provocada pela fragilidade do filho. Tais mães enfrentam uma fase de sentimentos de medo, de estresse, de dúvidas, de angústia, de insegurança e, junto a esses, vêm as pressões de familiares e amigos quanto à sua capacidade de amamentar, além de viverem cercadas de mitos e tabus relacionados ao aleitamento materno.

Os conselhos e opiniões de pessoas próximas e de profissionais de saúde são elementos significativos na avaliação que a mãe faz do estado alimentar de sua criança prematura e da sua capacidade em a atender. Esses elementos podem reforçar a confiança no seu desempenho de amamentar ou contribuir para um sentimento de insegurança, podendo, esta situação levar ao desmame precoce ${ }^{13,20}$.

\section{Sobre o método mãe-canguru}

O Método Mãe-Canguru tem como objetivo principal oferecer assistência integral e humanizada aos prematuros, sendo considerado também como um dos fatores que facilita a prática do aleitamento materno a esses recém-nascidos ${ }^{21,22}$.

Um dos critérios de elegibilidade para a permanência na enfermaria Mãe-canguru é que a mãe realmente queira participar e tenha tempo disponível; portanto, a equipe de saúde deve sempre propor e nunca impor a técnica. Sendo assim, das oito mães entrevistadas, apenas quatro participaram do método.

A permanência na referida enfermaria significou, para essas mães, a possibilidade de favorecer o desenvolvimento e o ganho de peso mais rápido a criança e, conseqüentemente, a alta hospitalar mais precoce:

Eu achei que o Canguru foi bom para o desenvolvimento dela, porque eu achava que ela não se criava, e no Canguru ela se desenvolveu bastante (M.E.G.A.). Ela tinha que pegar o pesinho dela pra poder vir pra casa, eu tinha que ter paciência de ficar com ela lá no Canguru (L.G.A.).

Esse método, além de proporcionar ao prematuro um bom desenvolvimento e ganho de peso satisfatório, aumenta o vínculo familiar; mãe 
e filho permanecem juntos, facilitando o estímulo ao aleitamento materno; diminuindo as infecções hospitalares e o tempo de permanência do recémnascido na incubadora, aumentando, com isso, a oferta de leitos nas unidades neonatais ${ }^{21,23}$.

Em seus relatos, as mães enfatizam que aprenderam na enfermaria Mãe-canguru a oferecer o seu próprio leite, no copinho ou na colher:

Saí do Canguru menos preocupada, mais satisfeita, mais confiante de que ela ia se criar e de que ia tudo dar certo, e deu, até hoje, graças a Deus (M.E.G.A.).

No Canguru, as enfermeiras [auxiliares de enfermagem] mandavam tirar o leite no copinho descartável, eu só conseguia tirar meio copinho, nunca dava a dieta completa dela, mas eu tinha que aprender a tirar o leite, pra quando chegasse em casa saber dar pra ela no copinho (C.G.S.).

Na enfermaria Mãe-canguru, as mães aprendem a complementar as mamadas, ofertando, no copinho ou colher, seu leite posterior, o qual contém mais gordura que o anterior, objetivando que seu filho ganhe peso mais rapidamente. Esse complemento é continuado em casa, até que o pediatra do Ambulatório de follow-up oriente a mãe sobre a suspensão ${ }^{15,24}$.

O único ponto negativo referido pelas entrevistadas quanto ao Método Mãe-Canguru diz respeito às acomodações, pois as mesmas devem dormir em posição semi-sentada, enquanto que a criança deve ficar junto ao seio materno, em posição vertical:

Eu achei um pouquinho ruim por causa da dormida com ela em cima de mim. Eu nunca fui de dormir de papo pra cima, só durmo emborcada, eu tinha que dormir quase sentada com ela. Cansava, ficava quente por causa da fralda descartável que ela usava (C.G.S.).

Quando ela estava dentro de mim, achei que ela ia ficar sufocada, sem fôlego. Pra mim, eu estava querendo tirar ela de dentro, ficar só com ela nos braços [...] (L.G.A.).
Cabe assinalar que tal circunstância não deve ser tomada como falha na estrutura ofertada às mães; apesar de a posição canguru ser incômoda para algumas mães, é necessária no método, pois é uma postura que evita a perda de calor do prematuro, a partir do contato com o corpo materno, propiciando uma termo regulação. Na concepção do método, durante esse contato mais íntimo com a mãe, o recém-nascido recebe carinho, escuta a voz e os batimentos cardíacos da mãe. Ao sugar, a criança regula os movimentos respiratórios, prevenindo, inclusive, quadros como apnéia, refluxos e aspiração pulmonar 23,24 .

Por fim, cabe registrar que, mesmo vivenciando situações peculiares, as mães desses prematuros optaram pelo aleitamento materno exclusivo.

\section{O N C L U S Ã O}

A partir da análise compreensiva dos depoimentos, apreendeu-se que cada mãe vivencia a amamentação de maneira única, singular e própria. Amamentar exclusivamente é visto como um dever/responsabilidade da mulher, como mãe, de dar o melhor de si para que seu filho tenha saúde, principalmente por ser prematuro. Esse fato se sobrepõe ao seu desejo ou não de querer fazê-lo. Para essas mães, o mais importante é priorizar o bem-estar de sua criança, muitas vezes em detrimento do seu próprio.

O reconhecimento das vantagens do leite materno para o prematuro foi o principal motivo apresentado pelas entrevistadas para amamentarem exclusivamente, mesmo diante de várias situações de insegurança, incômodo e desconforto. Curiosamente, não foi evidenciado espontaneamente pelas mães entrevistadas a ajuda dos pais, no processo de amamentação dos prematuros. Esse fato pode ter ocorrido, porque não houve aprofundamento da investigação sobre o suporte familiar pela entrevistadora, o que necessita ser pesquisado em outros estudos com esse grupo de mulheres. 
Com base nos relatos, constatou-se a necessidade de profissionais de saúde treinados para realizar atendimento, preferencialmente por intermédio de equipe interdisciplinar junto às mães desse grupo de crianças. Esses profissionais devem assisti-las desde o primeiro contato com seu filho, ajudando-as a elaborar a perda do bebê imaginado, reduzindo o medo de que ele venha a óbito, estimulando-as a expressar seus sentimentos, visando a aliviar suas ansiedades e angústias, principalmente relacionadas à prática da amamentação.

Para promover o aleitamento materno exclusivo de prematuros, sugere-se que o atendimento direto às mães seja, portanto, realizado por uma equipe de profissionais especializados, treinados nas técnicas de aconselhamento em amamentação, orientando-as e as ajudando, quando necessário, durante toda a internação do recém-nascido e, também, nas consultas no Ambulatório de follow-up.

Acredita-se que, para o sucesso da amamentação exclusiva da criança prematura, são fundamentais a determinação e o desejo da mãe para amamentar, além da atuação efetiva dos serviços e dos profissionais de saúde em prol do aleitamento materno.

Dessa forma, a amamentação não deve ser vista como responsabilidade exclusiva da mulher, que está envolvida em sentimentos, emoções e contradições, mas, sim, de todo o contexto sócio-histórico-biológico que extrapola o binômio mãe-filho.

\section{COLABORADORES}

D.F. BRAGA participou da concepção do estudo, desenvolveu o trabalho de campo e a análise do material. Redigiu o artigo na versão preliminar, participando, ainda, da revisão final. M.M.T. MACHADO participou da concepção do estudo, orientou o desenvolvimento da pesquisa e a análise do material, participando, ainda, da revisão final do artigo. M.L.M. BOSI participou da revisão da análise do material discursivo e da construção da versão do artigo submetido à publicação, bem como da redação da versão final.

\section{REFERÊ NCIAS}

1. Teruya KM, Coutinho SB. Sobrevivência infantil e aleitamento materno. In: Rego JD. Aleitamento materno. Rio de Janeiro: Atheneu; 2002.

2. Fundo das Nações Unidas para a Infância. Situação da infância brasileira 2006. Brasília; 2005.

3. Monteiro CA. Velhos e novos males da saúde no Brasil: a evolução do país e de suas doenças. $2 a$. ed. São Paulo: Hucitec; 2000.

4. Ceará. Secretaria da Saúde do Estado do Ceará. A saúde no Ceará em grandes números: uma avaliação da situação de saúde e das ações implementadas pelo Sistema Público Estadual. Fortaleza; 2006.

5. Almeida JAG. Amamentação: um híbrido natureza-cultura. Rio de Janeiro: Fiocruz; 1999.

6. Sikorski J, Renfrew MJ, Pindoria S, Wade A. Support for breastfeeding mothers: a systematic review. Pediatr Perinatal Epidemiol. 2003; 17(4):407-17.

7. Vinagre RD, Diniz EMA. O leite humano e sua importância na nutrição do recém-nascido prematuro. São Paulo: Atheneu; 2002.

8. Matuhara AM. Aleitamento materno de recémnascidos prematuros em unidade de terapia intensiva neonatal: aplicação do manual instrucional [tese]. São Paulo: Universidade Federal de São Paulo; 2004.

9. Bosi MLM. Mercado FJM. Pesquisa qualitativa de serviços de saúde. Petrópolis: Vozes; 2004.

10. Amatuzzi MM. Apontamentos acerca da pesquisa fenomenológica. Estud Psicol (Campinas). 1996, 13(1):5-10.

11. Tesch R. Qualitative research: analysis, type \& software tools. New York: The Falmer Press; 1995.

12. Santoro Jr W, Santoro A. Reações psicológicas e processo adaptativo de pais de recém-nascidos pré-termo e de muito baixo peso em Unidades de Terapia Intensiva Neonatal (UTIN). Rev Paul Pediatr. 2002; 20(2):95-101.

13. Javorski M, Caetano LC, Vasconcelos MGL, Leite AM, Scochi CGS. As representações sociais do aleitamento materno para mães de prematuros em unidade de cuidado canguru. Rev Latinoam Enferm. 2004; 12(6):890-8.

14. Bueno LGS, Teruya KM. Aconselhamento em amamentação e sua prática. J Pediatr. (Rio de Janeiro). 2004; 80:(Supp I 5):S126-S30.

15. Serra SOA, Scochi CGS. Dificuldades maternas no processo de aleitamento materno de prematuros em uma UTI neonatal. Rev Latinoam Enferm. 2004; 12(4):597-605. 
302 D.F. BRAGA et al.

16. Nascimento MBR, Issler H. Breastfeeding: making the difference in the development, health and nutrition of term and preterm newborns. Rev Hosp Clin Fac Med Univ São Paulo. 2003; 58(1): 49-60.

17. Vannuchi MTO, Monteiro CA, Réa MF, Andrade SMDE, Matsuo T. Iniciativa Hospital Amigo da Criança e aleitamento materno em unidade de neonatologia. Rev Saúde Pública. 2004; 38(3): 422-8.

18. Machado MMT. A conquista da amamentação: o olhar da mulher [dissertação]. Fortaleza: Universidade Federal do Ceará; 1999.

19. Araújo RMA, Guerra de Almeida JA. Aleitamento materno: o desafio de compreender a vivência. Rev Nutr. 2007; 20(4):431-8.

20. Silva IA. Amamentar: uma questão de assumir riscos ou garantir benefícios. São Paulo: Robe Editorial; 1997.
21. Venâncio SI, Almeida H. Método Mãe Canguru: aplicação no Brasil, evidências científicas e impacto sobre o aleitamento materno. J Pediatr (Rio de Janeiro). 2004; 80:(Suppl 5):S173-S80.

22. Duarte ED, Sena RR. Experiências de mulheres no desenvolvimento do método canguru. Rev Min Enferm. 2004; 8(4):436-41.

23. Acosta DR, Vara C, Omar L, Fuentes G, Juan M, Iglesias $C D$, et al. Método piel a piel. Evaluación clínica-humoral durante el primer año de edad. Rev Cuba Pediatr. 2003; 75(3).

24. Grazziotin MCB, Yamasaki IS. Acompanhamento de recém-nascidos prematuros em ambulatório de amamentação do banco de leite humano. Cogitare Enferm. 2000; 5(2):66-8.

Recebido em: 9/2/2007

Versão final reapresentada em: 6/11/2007 Aprovado em: 29/2/2008 